\title{
Uréter retrocavo
}

\author{
B. Juaneda, M. Musquera, J.I. Ochoteco*, F. Izquierdo*, H. Villavicencio Mavrich
}

Servicios de Urología y Radiología*. Fundació Puigvert. Hospital Santa Creu i Sant Pau. Barcelona.

Actas Urol Esp 2005; 29 (9): 1001

$\mathrm{P}$ aciente mujer de 25 años de edad que a raíz de dolor lumbar derecho se realizó ecografía que mostró moderada ectasia de la vía urinaria derecha hasta la región lumbar media, presentando un trayecto tortuoso en su porción proximal (Fig. 1).

La UIV mostró dilatación pielocalicilar y ureteral lumbar, con acodadura y proyección posteriomedial del mismo ("signo del saxo"), ante la sospecha de un trayecto ureteral anómalo retrocavo (Figs. 2 y 3), se realizó tomografía axial computarizada abdominal que confirmó el diagnóstico.

Dra. B. Juaneda Castell

Perelló, $80-5^{\text {o }}-1^{\text {a }}-08095$ Barcelona

(Trabajo recibido el 3 de febrero de 2005)

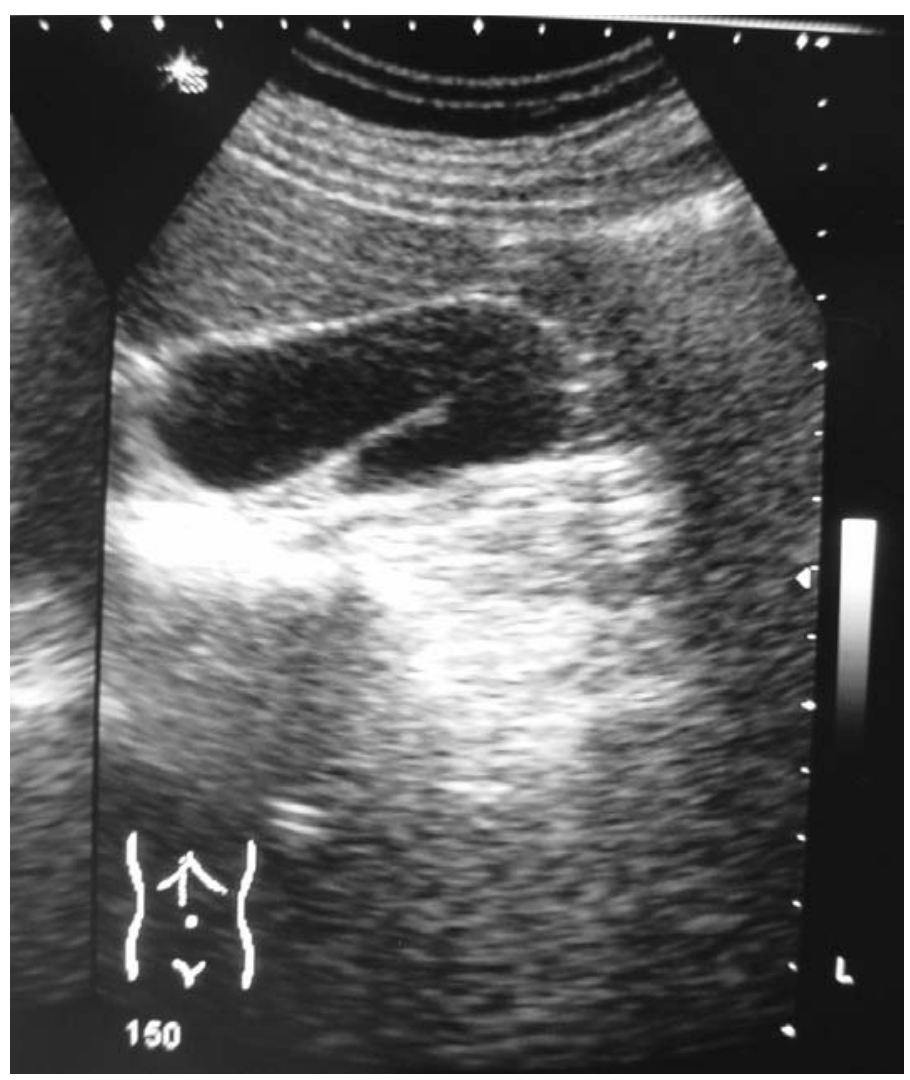

FIGURA 1

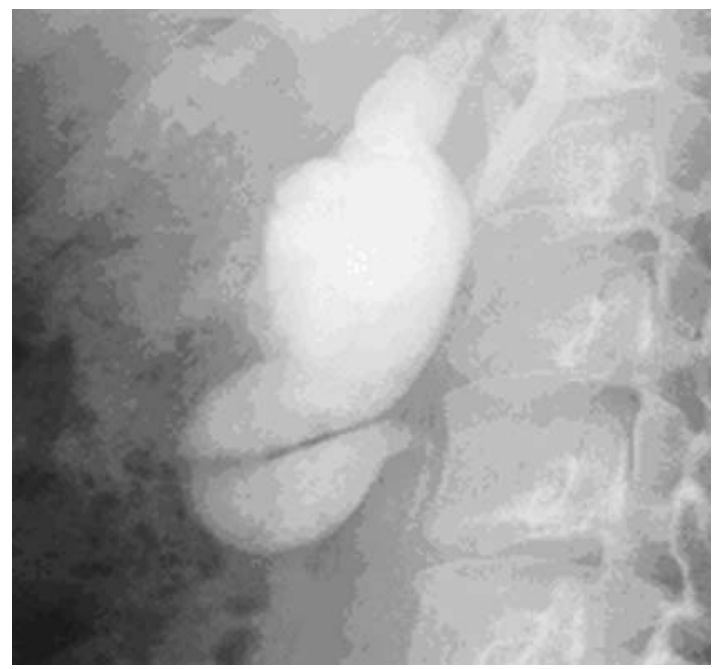

FIGURA 2

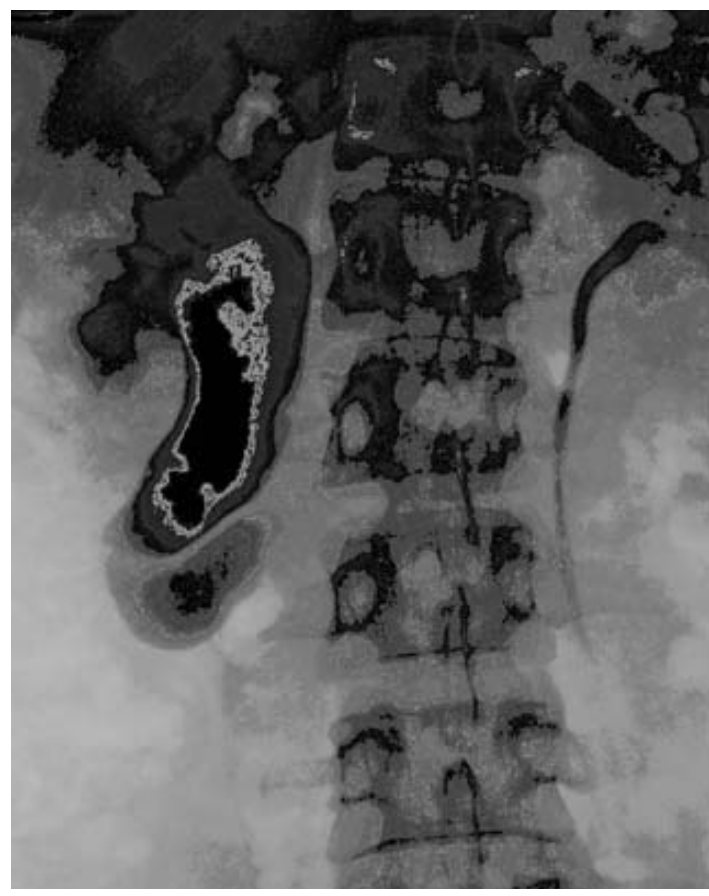

FIGURA 3 